\title{
Qualitative characteristics of the muscle tissue in young geese
}

\author{
Denis Osepchuk ${ }^{1}$, Andrey Svistunov ${ }^{1, *}$, Natalya Agarkova ${ }^{1}$, and Daria Astakhova ${ }^{1}$ \\ ${ }^{1}$ Krasnodar Research Centre for Animal Husbandry and Veterinary Medicine, 4, Pervomayskaya Str., \\ Znamensky village, Krasnodar, 350055, Russia
}

\begin{abstract}
The effect of complete compound feed (CCF) with a different level of crude fat, due to the use of sunflower oil (SO), on the qualitative characteristics of muscle tissue in young Linda geese was studied. The introduction of SO into the composition of CCF contributed to an increase in the concentration of linoleic acid in it by $43-47 \%$. No statistically significant differences were found in the chemical composition of the muscle tissue of the chest and legs. The best flavour had the meat of geese fed CCF with introduction of SO. The inclusion of SO in goslings rations did not negatively affect the serum biochemical composition of young geese up to 60 days of age.
\end{abstract}

\section{Introduction}

In modern poultry farming, fat is a natural component of feed mixtures, an additive that increases energy value, and a factor that improves the consistency and feed flavour. Vegetable fats, such as soybean and sunflower oil, as well as animal fats: beef, bone and combined poultry are commonly used $[1,2]$.

Fats and oils have the highest calorie content of all known nutrients. In recent years, because of the ever-increasing energy costs, there has been growing interest in maximizing the use of fat supplements, as nutritionists seek to increase the concentration of energy in the diet to meet the needs of modern highly efficient poultry [3].

The type of the fat used in diet formulation can affect growth rates, the composition of fatty acids in various tissues, poultry health, and the nutritional value of poultry products [4].

Typically, from 20 to $50 \mathrm{~g} / \mathrm{kg}$ of fat is added to poultry diets, depending on the relative prices of fat and grain. The addition of fats above $40 \mathrm{~g} / \mathrm{kg}$ is avoided in granular feed, usually due to the negative impact on the quality of the granules [5]. However, thanks to new technologies, more than $40 \mathrm{~g} / \mathrm{kg}$ of fat can be added to these granules.

The agricultural organizations operating in the Russian Federation engaged in goose breeding receive the main income mainly from the sale of young animals to owners of personal subsidiary or peasant farms, as well as from the sale of eggs to hatcheries. The geese meat at the enterprises is obtained, as a rule, from unrealized young animals, culled replacement young animals or adult poultry after rearing on cheap available feeds. Such

\footnotetext{
* Corresponding author: a.swistunov@yandex.ru
} 
geese are sold in small batches during the festive winter months, without obtaining a substantial income due to long-term feeding. At the same time, in the "Soviet era" the technology of intensive feeding of young geese up to 56-60 days of age was widespread during the period of the most intensive chick growth and effective feed conversion. The carcass and meat of two-month-old geese contains less fat and more essential amino acids than a 12-month-old goose, although the proportion of pectoral muscle in the carcass of adult geese is greater.

Compared with the technology of growing chicken, in the diets for geese it is possible to significantly reduce the proportion of grain due to the inclusion of various grassy feeds rich in raw fiber. However, the industrial technology of rearing young geese for meat is based on the use of complete compound feed (CCF). The application of detailed standards of poultry feeding is an important aspect of increasing the feed conversion into products and, consequently, the economic efficiency of the industry.

The current Russian recommendations for fattening young geese provide for the use in diets of up to $5 \%$ by weight of various feed fats, which increases the total crude fat content in the diet up to $10 \%$ on an average. However, the studies of D. V. Osepchuk et al. (2018) showed a decrease in the growth rate and economic efficiency of poultry farming even with an increase of total raw fat content in PC up to 7.8\% [6]. The latter indicates the advisability of rationing raw fat in diets for young geese. At the same time, feed lipids have a significant impact on the qualitative composition and taste properties of muscle tissue and human food derived from it. Therefore, in this work, we studied the effect of CCF with different levels of crude fat on the chemical and fatty acid composition, organoleptic properties of the muscle tissue of young geese, as well as the biochemical composition of their blood serum depending on the level of crude fat and linoleic acid in complete feeds.

\section{Materials and methods}

In the vivarium of the Krasnodar Research Centre for Animal Husbandry and Veterinary Medicine (Krasnodar), studies were conducted on goslings of the Linda breed.

The daily goslings were distributed into 4 groups of 36 animals each using analogue pairs method. The males and females were kept separately in groups of 18 animals. Young geese of the first and second groups in the initial period of growing were fed CCF with $5.5 \%$ crude fat (Table 1 ).

Table 1. Experimental design $(\mathrm{n}=36:$ : +18 ; $\widehat{\partial}-18)$.

\begin{tabular}{|c|c|c|c|}
\hline \multirow{2}{*}{ Group } & \multicolumn{3}{|c|}{ Period of growing, days } \\
\hline & 1-3 (equilizing) & 4-28 (start) & 29-60 (finish) \\
\hline 1-control & \multirow{4}{*}{$\begin{array}{c}\text { Complete compound } \\
\text { feed (CCF) without } \\
\text { sunflower oil (SO) }(5.5 \\
\% \text { crude fat }(\mathrm{CF}))\end{array}$} & \multirow{2}{*}{$\begin{array}{c}\text { CCF without } \\
\text { SO } \\
(5.5 \% \mathrm{CF})\end{array}$} & $\mathrm{CCF}_{1}$ without $\mathrm{SO}(4.9 \% \mathrm{CF})$ \\
\hline 2-experimental & & & $\mathrm{CCF}_{1}$ with $2 \% \mathrm{SO}(6.9 \% \mathrm{CF})$ \\
\hline 3-experimental & & \multirow{2}{*}{$\begin{array}{c}\text { CCF with } 2 \% \\
\text { SO } \\
(7.4 \% \mathrm{CF})\end{array}$} & $\mathrm{CCF}_{1}$ without $\mathrm{SO}(4.9 \% \mathrm{CF})$ \\
\hline 4-experimental & & & $\mathrm{CCF}_{1}$ with $2 \% \mathrm{SO}(6.9 \% \mathrm{CF})$ \\
\hline
\end{tabular}

Sunflower oil at the rate of $2 \%$ was introduced in the starter CCF for geese of the third and fourth groups, respectively, the level of crude fat increased to $7.4 \%$. In the finishing period, the level of crude fat was increased to $6.9 \%$ due to the introduction of $2 \%$ sunflower oil in compound feeds for young geese of the second and fourth groups. In the feed for geese of the first and third groups, no sunflower oil was introduced into the finishing period of fattening: the level of crude fat in the finishing CCF was $4.9 \%$.

The introduction of sunflower oil in the starter and finishing $\mathrm{CCF}$ contributed to an increase in the concentration of linoleic acid in diets for young geese by $43-47 \%$. 
The analysis of the chemical and fatty acid composition of the pectoral muscle tissue, lower leg and thigh of geese was carried out according to generally accepted methods. The content of crude fat in CCF and fat in muscle tissue was determined by the Soxhlet method, the fatty acid composition of muscle tissue was determined by gas-liquid chromatography on the Tsvet-5 chromatograph.

To determine the organoleptic properties of goose meat, a tasting assessment of the muscle tissue of the chest and legs, as well as the broth on a 5-point scale was performed

\section{Research results}

The increase in crude fat content in starter and finishing CCF due to the use of sunflower oil did not have a significant effect on the nutrient content in the muscle tissue of geese (Table 2).

Table 2. Chemical composition of the muscle tissue in geese, $M \pm m(n=\hat{O}-3 ;$; -3$)$.

\begin{tabular}{|c|c|c|c|c|c|}
\hline & \multirow{2}{*}{ Components } & \multicolumn{4}{|c|}{ Group } \\
\hline & & 1 & 2 & 3 & 4 \\
\hline \multicolumn{6}{|c|}{ Pectoral muscles } \\
\hline & Moisture, $\%$ & $76.0 \pm 0.6$ & $76.4 \pm 0.5$ & $75.9 \pm 0.3$ & $74.3 \pm 0.1$ \\
\hline \multirow{2}{*}{ 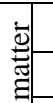 } & Protein, $\%$ & $82.4 \pm 3.5$ & $83.5 \pm 0.4$ & $86.7 \pm 2.3$ & $80.1 \pm 0.6$ \\
\hline & Fat, \% & $14.2 \pm 3.4$ & $10.9 \pm 0.1$ & $10.3 \pm 0.8$ & $16.0 \pm 0.1$ \\
\hline 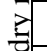 & Calcium, mg/100g & $57.3 \pm 1.3$ & $56.6 \pm 1.8$ & $57.6 \pm 0.8$ & $51.3 \pm 0.41 *$ \\
\hline.$\Xi$ & Phosphorus, mg/100g & $757.2 \pm 12.2$ & $854.1 \pm 111.1$ & $682.3 \pm 25.5$ & $849.2 \pm 3.6^{*}$ \\
\hline \multicolumn{6}{|c|}{ Thigh and lower leg muscles } \\
\hline \multicolumn{2}{|r|}{ Moisture, $\%$} & $73.9 \pm 0.96$ & $72.8 \pm 0.13$ & $72.7 \pm 0.14$ & $72.4 \pm 0.14$ \\
\hline \multirow{4}{*}{ 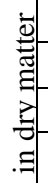 } & Protein, $\%$ & $78.5 \pm 3.06$ & $76.8 \pm 1.47$ & $78.3 \pm 0.23$ & $76.1 \pm 0.67$ \\
\hline & Fat, $\%$ & $18.6 \pm 1.20$ & $19.6 \pm 0.50$ & $18.6 \pm 0.32$ & $21.8 \pm 0.23$ \\
\hline & Calcium, mg/100g & $48.6 \pm 6.4$ & $49.2 \pm 1.05$ & $48.9 \pm 0.8$ & $49.6 \pm 0.50$ \\
\hline & Phosphorus, mg/100g & $758.0 \pm 24.1$ & $747.9 \pm 21.7$ & $602.1 \pm 3.1 *$ & $564.9 \pm 26.5^{*}$ \\
\hline
\end{tabular}

Note: * - P $\leq 0.05$.

At 60 days of age, goslings have a high protein content in the dry matter of the pectoral muscles -83.5 and $86.7 \%$, or $1.1 \%$ and $4.3 \%$ higher than the control value, respectively. At the same time, the concentration of fat was lower than in the control by 3.3 and $4.1 \%$, respectively.

The inclusion of SO in the finishing $\mathrm{CCF}$ of goslings of the second group increased the fat content in the dry matter of the thigh muscles by $1.0 \%$, with a decrease in protein by $1.7 \%$, compared with the control group.

In the goslings of the fourth group, to the composition of CCF of which sunflower oil was added during the entire growing period, there was a tendency to less accumulation of moisture and protein in the pectoral and femoral muscles, and more fat deposit by 1.8 and $3.2 \%(\mathrm{P}>0.05)$.

In our previous studies, a tendency toward a decrease of calcium concentration and an increase in the proportion of phosphorus in the muscle tissue of the geese of the experimental groups with an increase in the level of crude fat in starter CCF was noted [7, 8].

In the results of this experiment (third group), a trend from previous studies is not observed. Therefore, even the significant differences in the levels of calcium and phosphorus found in the third and fourth groups can be random. 
From the results of the study, it can be concluded that the developed CCF do not adversely affect the chemical composition of the muscle tissue of young geese.

An important feature of the biological value of muscle tissue can also include the fatty acid composition of its lipids. The inclusion of sunflower oil in the composition of the PC for young geese of the experimental groups led to an increase in the concentration of linoleic acid in the diet. Analysis of the fatty acid composition of lipids in the muscles of the chest and legs did not reveal any regular changes depending on the studied nutritional factors (Fig. 1 and 2).

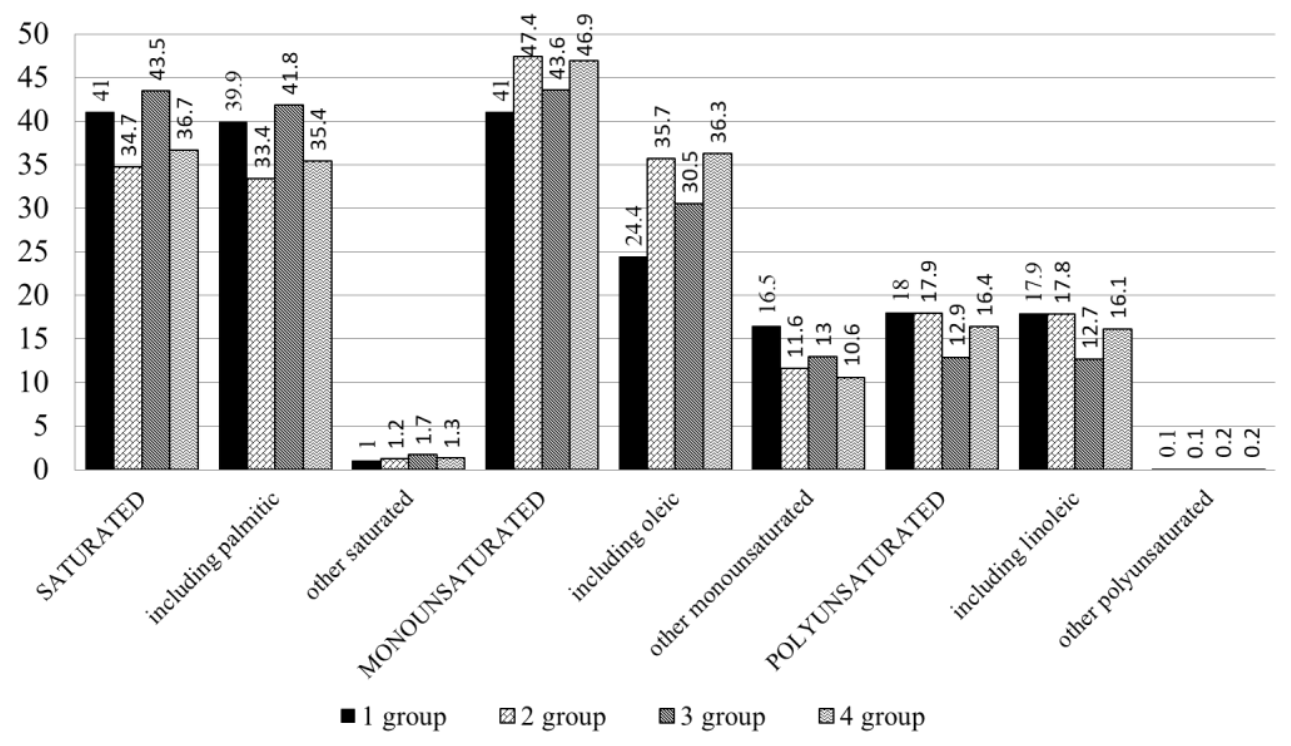

Fig. 1. The specific gravity of fatty acids in the fat of the pectoral muscle, $\%$.

The fatty acid composition of lipids in muscle tissue is more determined by the genetic characteristics of individual species, breeds, and even crosses of birds than by feeding factors. But, a shortage or excess of essential fatty acids can to some extent affect the chemical composition of the tissues of the animal body.

The specific gravity of linoleic acid $17-20 \%$ of the total amount of fatty acids in muscle tissue lipids, determined by us, is comparable with the results of studies of the muscles in broiler chickens and ducks in the experiment of Halle I. et al. (2012), but significantly different to a large extent from the data of Ebrahim R. et al. $(2015)[9,10]$.

At the same time, as in broiler chickens (I. Halle et al., 2012), in young geese, the relative content of linoleic acid in the leg muscles was slightly higher than in the muscle tissue of the breast [9].

With an increase in the concentration of crude fat in CCF, mainly due to unsaturated fatty acids, both during the entire growing period and only in the finishing period, there is a tendency to increase the proportion of monounsaturated fatty acids in the lipid fraction of the pectoral and leg muscles of young geese.

The specific gravity of oleic acid was greater in the second and fourth groups by 11.3 and $11.9 \mathrm{abs} \%$ in fat of the pectoral muscle, and by 2.2 and 2.0 abs \% in the leg muscles, compared with the first - control group. Moreover, in the muscle fat of the geese of the second and fourth experimental groups, a decrease in the proportion of palmitic acid by 1.8 6.5 abs. $\%$ and in general saturated fatty acids by 2.1-6.3 abs.\% was observed. 


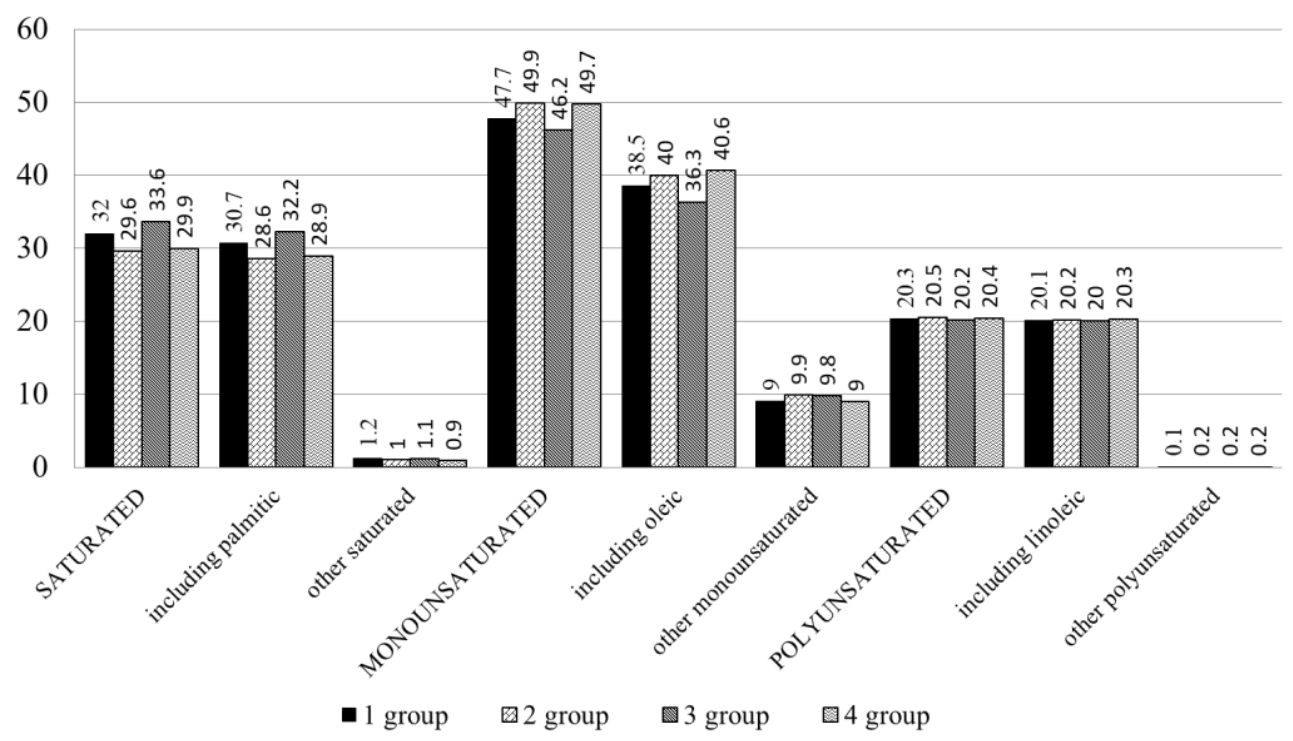

Fig. 2. The specific gravity of fatty acids in the fat of leg muscle, $\%$.

Thus, the inclusion of sunflower oil in the finishing diets for young geese contributes to a greater accumulation of monounsaturated oleic acid in muscle fat while reducing the content of saturated palmitic acid, which is preferable from the point of view of human nutrition.

The nutritional value of meat depends on the quantitative ratio of water, protein, fat, the content of essential amino acids, polyunsaturated fatty acids, vitamins, micro and macro elements in it. However, the nutritional and taste benefits of meat are largely determined by the quantity and quality of fat in muscle tissue.

To determine the effect of the inclusion of sunflower oil in the diets for young geese, a tasting assessment of the pectoral and leg muscles of the studied poultry was carried out, the results of which are presented in table 3 .

Table 3. Organoleptic evaluation of meat of geese, points.

\begin{tabular}{|l|c|c|c|c|}
\hline \multirow{2}{*}{ Items } & \multicolumn{4}{c|}{ Group } \\
\cline { 2 - 5 } & $\mathbf{1}$ & $\mathbf{2}$ & $\mathbf{3}$ & $\mathbf{4}$ \\
\hline \multicolumn{5}{|c|}{ Pectoral muscles } \\
\hline Aroma & 4.3 & 4.0 & 4.3 & 4.5 \\
\hline Taste & 4.2 & 4.3 & 4.3 & 4.3 \\
\hline Tenderness (stiffness) & 4.0 & 4.5 & 3.7 & 4.3 \\
\hline Juiciness & 4.0 & 4.5 & 3.8 & 4.5 \\
\hline Total & 16.5 & 17.3 & 16.1 & 17.6 \\
\hline \multicolumn{5}{|c|}{ Thigh and lower leg muscles } \\
\hline Aroma & 4.0 & 4.2 & 4.0 & 4.5 \\
\hline Taste & 4.0 & 4.5 & 3.8 & 4.2 \\
\hline Tenderness (stiffness) & 3.7 & 4.0 & 3.7 & 4.2 \\
\hline Juiciness & 3.5 & 4.2 & 3.5 & 4.2 \\
\hline Total & 15.2 & 16.9 & 15.0 & 17.1 \\
\hline
\end{tabular}

The meat of the geese, which received CCF with sunflower oil in the finishing period of growing, was characterized by higher organoleptic characteristics, had a more pronounced taste and aroma, as well as juiciness and tenderness. The final assessment of the samples of 
the pectoral muscles of geese of these groups was 17.3-17.6 points, of the legs - 16.9 and 17.1 points out of 20 possible.

Samples of meat broth of all experimental groups were fragrant, having a straw color. The broth of the third group turned out to be the most transparent - 4.5 points, the geese of which received sunflower oil in the first growing period. In the remaining groups, the transparency of meat broth was estimated from 3.5 to 3.8 points. The broth of the second group in terms of taste and richness was evaluated at 4.3 and 4.0 points, and the fourth - at 4.2 and 4.0 points, respectively (Table 4 ).

Table 4. Organoleptic evaluation of the broth, points.

\begin{tabular}{|l|c|c|c|c|}
\hline \multirow{2}{*}{ Items } & \multicolumn{4}{|c|}{ Group } \\
\cline { 2 - 5 } & $\mathbf{1}$ & $\mathbf{2}$ & $\mathbf{3}$ & $\mathbf{4}$ \\
\hline Aroma & 4.5 & 4.0 & 4.5 & 4.5 \\
\hline Taste & 4.0 & 4.3 & 4.0 & 4.2 \\
\hline Transparency & 3.7 & 3.5 & 4.5 & 3.8 \\
\hline Strength (richnss) & 3.8 & 4.0 & 3.7 & 4.0 \\
\hline Total & 16.0 & 15.8 & 16.7 & 16.5 \\
\hline
\end{tabular}

Thus, feeding young geese to finishing CCF with a crude fat content of $6.9 \%$ due to the inclusion of sunflower oil helps to improve the taste of goose meat and broth.

The chemical composition of the blood of animals is an important diagnostic of the state of the body and the direction of metabolism. The results of a blood test of geese taken from analogues at 60 days of age are presented in table 5 .

Table 5. Biochemical values of blood serum of young geese, $M \pm m(n=6: \delta \hat{~-~} 3$; -3$)$.

\begin{tabular}{|l|c|c|c|c|}
\hline \multirow{2}{*}{\multicolumn{1}{|c|}{ Items }} & \multicolumn{4}{c|}{ Group } \\
\cline { 2 - 5 } & $\mathbf{1}$ & $\mathbf{2}$ & $\mathbf{3}$ & $\mathbf{4}$ \\
\hline Total protein, g/l & $39.1 \pm 0.21$ & $37.3 \pm 2.42$ & $41.9 \pm 2.98$ & $39.6 \pm 1.23$ \\
\hline Albumins, g/l & $19.2 \pm 1.28$ & $19.0 \pm 1.51$ & $20.4 \pm 1.61$ & $18.0 \pm 1.21$ \\
\hline Globulins, g/l & $19.9 \pm 1.43$ & $18.4 \pm 1.41$ & $21.5 \pm 2.67$ & $21.6 \pm 2.16$ \\
\hline including: & & & & \\
$\alpha$-globulins & $7.6 \pm 0.42$ & $7.0 \pm 0.47$ & $8.3 \pm 0.68$ & $7.6 \pm 0.51$ \\
\hline$\beta$-globulins & $3.9 \pm 0.40$ & $3.0 \pm 0.44$ & $4.1 \pm 0.40$ & $4.8 \pm 0.57$ \\
\hline$\gamma$-globulins & $8.5 \pm 1.14$ & $8.4 \pm 11.4$ & $9.1 \pm 2.01$ & $9.3 \pm 1.52$ \\
\hline Glucose, mmol/1 & $9.2 \pm 0.53$ & $11.4 \pm 0.65$ & $10.5 \pm 0.38$ & $9.6 \pm 0.74$ \\
\hline Urea, mmol/ 1 & $2.5 \pm 0.05$ & $2.6 \pm 0.18$ & $2.5 \pm 0.11$ & $2.4 \pm 0.06$ \\
\hline Cholesterol, mmol/1 & $3.7 \pm 0.19$ & $4.1 \pm 0.34$ & $3.9 \pm 0.07$ & $4.3 \pm 0.34$ \\
\hline Alkaline phosphatase, IU & 2193.0 & 2900.8 & 2457.5 & 1868.3 \\
\hline Triglycerides, mmol / 1 & \pm 116.3 & \pm 368.7 & \pm 342.8 & \pm 144.3 \\
\hline AST, IU & $0.39 \pm 0.04$ & $0.35 \pm 0.04$ & $0.45 \pm 0.06$ & $0.43 \pm 0.04$ \\
\hline ALT, IU & $118.0 \pm 6.7$ & $118.8 \pm 6.2$ & $111.75 \pm 0.5$ & $112.0 \pm 1.2$ \\
\hline Calcium, mmol / & $23.5 \pm 3.07$ & $19.3 \pm 1.93$ & $23.8 \pm 2.95$ & $21.5 \pm 2.9$ \\
\hline Phosphorus, mmol / & $2.33 \pm 0.05$ & $2.25 \pm 0.06$ & $2.25 \pm 0.05$ & $2.30 \pm 0.04$ \\
\hline Zinc, mg\% & $2.43 \pm 0.06$ & $2.55 \pm 0.03$ & $2.55 \pm 0.1$ & $2.35 \pm 0.06$ \\
\hline Copper, mg\% & $184.7 \pm 22.7$ & $193.0 \pm 12.6$ & $195.8 \pm 30.1$ & $180.6 \pm 18.1$ \\
\hline
\end{tabular}

When assessing the biochemical constants of blood serum in geese at the end of the experimental period, the third experimental group showed a positive dynamics in increasing indicators of protein metabolism and stabilizing its qualitative composition. Thus, the level of total protein in geese of group 3 exceeded the values of control analogues by $7.16 \%$ and the concentration of albumin by $6.3 \%$. In other groups, a similar effect was not observed. 
By the level of glucose in geese of the second experimental group, the maximum increase in this metabolite was recorded relative to the control indicators (by 23.9\%). In the third experimental group, the glucose level by the end of the experiment increased by $14.1 \%$. The differences between the control and the fourth experimental groups were minimal, amounting to $4.3 \%$ in favor of the experimental geese.

An intergroup analysis of the blood lipid composition of geese revealed certain changes in cholesterol and triglycerides. For cholesterol, significant differences with control were found in all experimental geese. Moreover, in the second and fourth groups, the concentration of cholesterol exceeded the values of the control analogues by 10.8 and $16.2 \%$, while in the third group the increase was less pronounced, amounting to $5.4 \%$ without a statistically significant difference. The level of triglycerides was highest in the third and fourth experimental groups, exceeding the same control values by 15.4 and $10.3 \%$, respectively.

Analysis of other biochemical blood factors of geese (urea, calcium, phosphorus, aminotransferases) did not reveal significant changes. All determined values were within the norm of the species

\section{Conclusion}

In recent years, most of the researches in the field of feeding geese have been devoted to the use of various feed and biologically active additives [11-15]. At the same time, the level of raw fat in the diet has a significant effect on the concentration of metabolic energy, the efficiency of the use of nutrients and the chemical composition of the organs and tissues of the poultry.

From the results of the studies, it can be concluded that the use of CCF with the addition of sunflower oil in the finishing period or throughout the growing period contributed to an increase in the biological adequacy of fat in the muscle tissue of geese due to an increase in the content of monounsaturated fatty acids and an increase in the organoleptic properties of meat and broth. The negative effect of diets with different levels of crude fat on homeostasis in the body of young geese up to 60 days of age has not been established.

\section{References}

1. K. Burlikowska, A. Piotrowska, R. Szymeczko, J. Anim. Feed Sci. 19, 440-451 (2010) doi: 10.22358/jafs/66308/2010

2. M. Hossein Alimohammadi Saraee, A. Seidavi, M. Dadashbeiki, V. Laudadio, V. Tufarelli, Pak. J. Zool. 46, 1767-1773 (2014)

3. V. Ravindran, P. Tancharoenrat, F. Zaefarian, G. Ravindran, Animal Feed Science and Technology 213, 1-21 (2016)

4. K. Kanakri, J. Carragher, R. Hughes, B. Muhlhausler, R. Gibson, European Journal of Lipid Science and Technology 120, 1 (2018) doi: 10.1002/ejlt.201700237

5. M.R. Abdollahia, V. Ravindrana, B. Svihus, Anim. Feed Sci. Technol. 179, 1-23 (2013) doi: 10.1016/j.anifeedsci.2012.10.011

6. D.V. Osepchuk, A.A. Svistunov, N.A. Agarkova, Mater. V int. scientific Conf. The 25th anniversary of the foundation of Maykop State Technological University, 190-192 (2018) 
7. I.N. Barefoot D.V. Osepchuk, S.I. Kononenko, Polythematic Mathematical Electronic Scientific Journal of the Kuban State Agrarian University 120, 914-923 (2016) http://ej.kubagro.ru/2016/06/pdf/62.pdf

8. D.V. Osepchuk, A.N. Ratoshny, A.Yu. Shantyz, L.N. Skvortsova, Proceedings of the Kuban State Agrarian University 53, 198-202 (2015)

9. I. Halle, G. Jahreis, M. Henning, P. Köhle, S. Dänicke, Journal für Verbraucherschutz und Lebensmittelsicherheit 7, 3-9 (2012) doi: 10.1007/s00003-011-0749-5

10. R. Ebrahim, J. Boo Liang, M. Faseleh Jahromi, P. Shokryazdan, M. Ebrahimi, W. Li Chen, Y. Meng Goh, Italian Journal of Animal Science 14, 572-577 (2015)

11. J. Arroyo, A. Auvergne, J.P. Dubois, F. Lavigne, M. Bijja, C. Bannelier, H. Manse, L. Fortun-Lamothe, Poultry Science 92(9), 2448-2456 (2013) doi: 10.3382/ps.201303136

12. Hai-cheng Yin, J. Huang, Journal of Integrative Agriculture 15(9), 2077-2086 (2016) doi: 10.1016/s2095-3119(15)61198-4

13. Z.Y. Wang, H.M. Yang, J. Lu, W.Z. Li, J.M. Zou, Animal Feed Science and Technology 194, 99-105 (2014) doi: 10.1016/j.anifeedsci.2014.04.009

14. W. Chen, Y.Y. Jiang, J.P. Wang, Y.Q. Huang, Z.X Wang, Livestock Science 164, 102108 (2014) doi: 10.1016/j.livsci.2014.03.010

15. J. Biesek, J. Kuźniacka, M. Banaszak, M. Adamski, Animals 10(2), 200 (2020) doi: 10.3390/ani10020200 